\title{
O SABER TRADICIONAL: DISCUSSÔES NO ÂMBITO DA CDB E DO ACORDO OMC-TRIPS
}

Fernando Henrique Ribeiro de Almeida ${ }^{1}$

\section{RESUMO}

O presente artigo objetiva perpassar, mesmo que de forma introdutória, pela discussão acerca do saber tradicional, conceito este que encontra seu recorte semântico fundamentado em organizações internacionais. Salienta-se a importância do tema na ótica de um país em desenvolvimento. Segue-se com um breve retrospecto e a análise do discurso da Convenção sobre Diversidade Biológica, uma das bandeiras do hiato Norte-Sul. Posteriormente se faz outro retrospecto versando sobre a regulamentação do saber tradicional no Acordo da Organização Mundial do Comércio chamado Trips. Finalmente são elaboradas considerações sobre o que representam tais discussões nas relações internacionais e são demonstrados quatro pontos de tensão entre a CDB e o Acordo Trips.

\section{ABSTRACT}

This article has as an objective to go trough, in a sort of introductory form, issues concerning traditional knowledge, concept that finds its semantic shape based on international organizations. It evidences the importance of the subject to the developing country optics. A brief retrospect is followed and the speech analysis of the Convention on Biological Diversity, one flag to the NorthSouth hiatus. Later another retrospect is done aiming the regulation of traditional knowledge in the Trips Agreement from the World Trade Organization. Finally considerations are done on what such quarrels represent in the international relations and four points of tension are demonstrated between the CDB and the Trips Agreement.

\footnotetext{
${ }^{1}$ Especialista em Relações Internacionais pela UFPR e, nesta mesma, integrante do Núcleo de Direito Internacional no grupo de Propriedade Intelectual em 2006.
}

Revista Brasileira de Direito Internacional, Curitiba, v.4, n.4, jul./dez.2006 
Palavras-chave: Saber Tradicional. Convenção sobre Diversidade Biológica. Acordo Trips.

Key words: Traditional Knowledge. Convention on Biological Diversity. Trips Agreement.

\section{INTRODUÇÃO}

O debate acerca desse tema específico permeia a epistemé e vem aparecendo na literatura recentemente, assim como em deliberações nacionais e internacionais, a partir das crescentes preocupações com a proteção e uso do ambiente.

Muita credibilidade se deu ao progresso da ciência principalmente após o advento da revolução industrial. O mercantilismo que se transformou em capitalismo incipiente frutificava em mais e mais idéias, processos e regras para o progresso da humanidade. Com o desenvolvimento de pedagogias educacionais, de escolas técnicas e de universidades de cursos multidisciplinares adveio ao final do século XX, além de muita pesquisa e de mão de obra, uma problemática paradoxal.

Obviamente em muito esse desenvolvimento influiu no curso histórico do planeta, porém não só beneficamente. Se em uma via está o desenvolvimento fundado nos recursos naturais limitados em outra está à influência do desenvolvimento na qualidade do ambiente e na vida dos seres humanos.

As enormes transformações ambientais frutificaram literatura heterodoxa, criticando principalmente a lógica racional-economicista que não incluía e vêm tentando maquilar as nuâncias socioambientais. A ciência desenvolveu suas especificidades focadas na produtividade do capital e vem recebendo do discurso da interdisciplinariedade, ou seja, do desenvolvimento sustentável, severas solapadas.

Esta integração dos saberes que não apenas serve como "método e prática para a produção de conhecimentos e para sua integração operativa na 
explicação e resolução dos mais complexos problemas do desenvolvimento" 2 , vislumbra também o intercâmbio entre as disciplinas e que funda objetos no conhecimento e provoca profundas transformações nos antigos objetos.

Mas se nesse viés dos saberes ambientais a CDB representa para os países em desenvolvimento um canal de pressão nas questões a eles mesmos pertinentes, no outro extremo, altamente relevante para o ingresso no pequeno grupo dos países desenvolvidos, está a arena da OMC que juntamente com o acordo Trips. O difícil embate internacional do comércio vem postergando, ignorando e renegando a questão da formação de uma comunidade internacional fundada na cooperação e na integração.

Através de mecanismos jurídicos, políticos, econômicos e principalmente pela OMC, países desenvolvidos ainda defendem seus interesses e prezam por prolongar as desvantagens históricas entre os povos. Calcados no discurso mercantil-capitalista, que é por sua vez responsável em grande parte pelas desigualdades entre países do norte, desenvolvidos, e do sul, em suposto desenvolvimento. E obviamente nos dias de hoje, um discurso responsável pela problemática ambiental.

Ainda pior, é possível observar o lobby destes interesses de monopólios e oligopólios industriais influindo na população imoral e elitista detentoras do poder econômico e da capacidade de mudança. Ainda assim são formadores de opinião através dos meios de comunicação, atingindo tanto as camadas mais abastadas quanto as camadas mais humildes. Como enfatiza a professora Patrícia Aurélia Del Nero com relação aos oligopólios:

\footnotetext{
"Cumpre destacar que os grandes produtores da biotecnologia são os grandes conglomerados transnacionais, verdadeiros ícones do capitalismo institucionalizado pela modernidade que plantam suas sementes, vendem seus remédios, manipulam e dominam a pesquisa, seduzem os pesquisadores, com "complementação de salários" em dólar e a possibilidade de participação nos royalties.",
}

\footnotetext{
${ }^{2}$ LEFF, Enrique. Epistemologia ambiental. São Paulo: Editora Cortês, 2001. p. 68 . O autor traz neste livro farta relação entre conceitos como racionalidade, saber, formação econômica, formação social e seus paradigmas capitalistas frente à crise ambiental.

${ }_{3}$ NERO, Patrícia Aurélia Del. A Propriedade Intelectual da Biotecnologia. In: CARVALHO, Patrícia Luciane de. (Coord.) Propriedade intelectual: estudos em homenagem à professora Maristela Basso. Curitiba: Juruá, 2005. p. 360.
} 
Com relação à titularidade das patentes:

“(...) o detentor desses direitos - tanto no campo da apropriação da Biotecnologia por meio de patentes de invenção, quanto no campo do direito do melhorista, normalmente é a pessoa jurídica - pública ou privada - o que gera também a exclusão e a expropriação da força do trabalho do pesquisador ou inventor; aquele que concebeu e realizou o objeto da patente ou a nova cultivar ou a cultivar essencialmente derivada. Sendo assim, o inventor, aquele que efetivamente transforma potencialidades criativas e inventivas em tecnologia, possui apenas as sobras do banquete da propriedade intelectual, ou seja, apenas a participação nos royalties."

Serão feitos então breves comentários a respeito do saber tradicional, da CDB e posteriormente da OMC-Trips. Sempre visando manter no recorte analítico as questões que envolvem o saber e as práticas tradicionais, seus usos, o acesso a esses conhecimentos e a repartição de seus benefícios.

\section{O SABER TRADICIONAL}

Apesar da ciência, no decorrer da história, aparentar uma espécie de contraposição à natureza, conseqüência do próprio desenvolvimento científico, acontece ultimamente uma espécie de movimento oposto. Isso no sentido de que se alguém idealizou, através do próprio conhecimento científico, instrumentos propiciadores de uma "autonomia" dos humanos na terra e assim poderiam estar despreocupados com recursos naturais escassos.

$\mathrm{Na}$ segunda Revolução Industrial a Alemanha desponta nos estudos de fármacos aos fins do século XIX. Experiências eram feitas a partir dos corantes na busca de medicamentos mais acessíveis (sintéticos) para a gripe, como a influenza que assolou a Europa em 1889, para a sífilis, a tuberculose a malária. Como bem narrado por Catelli:

\footnotetext{
"A única forma conhecida de combate à febre na Europa até a criação da Antipirina era o consumo de um produto feito à base de casca de cinchona, árvore natural de Java, da família das rubiáceas, a mesma do café. A casca de cinchona era usada desde o século XVII no combate as doenças tropicais, especialmente a malária. Foi levada para a Europa provavelmente em 1642 e
}

\footnotetext{
${ }^{4}$ NERO, Patrícia Aurélia Del. A Propriedade Intelectual da Biotecnologia In: CARVALHO, Patrícia Luciane de. (Coord.) Propriedade intelectual: estudos em homenagem à professora Maristela Basso. Curitiba: Juruá, 2005. p. 360.
} 
vendida por muito tempo como um remédio secreto dos jesuítas. Dois séculos mais tarde, pesquisas laboratoriais revelaram que a casca da cinchona era composta basicamente de quinina, produto natural extraído de plantas como a quina-amarela e outras congêneres." 5

Continua o autor:

\begin{abstract}
"Este produto, no entanto, além de ter uma eficácia relativa, tinha um custo excessivamente alto, uma vez que o processo de importação, além de caro, tornava-o escasso e de difícil obtenção. Assim a produção industrial da Antipirina tornou-se mais eficaz e muito mais barato o combate à febre, o que era essencial para várias doenças, como a tuberculose." 6
\end{abstract}

Mas somente após as duas grandes guerras os trabalhos de antropólogos, etnólogos, etnobotanistas, químicos e ambientalistas que prezaram na literatura científica pelos modos de vida ditos indígenas ou locais tomaram certa importância. As comunidades que viviam e tinham conhecimentos do ambiente, começaram a ter grande relevância econômica tanto legal como ilegalmente após os anos 60 . A febre dos enteógenos ${ }^{7}$ persiste até os atuais dias e se buscam usos para fins científicos, comerciais e recreacionais de diversas substâncias.

A posterior aplicação prática de uma série de outras substâncias ${ }^{8}$ e estas provindas de um saber que vinha da convivência direta de comunidades com o ambiente, assim não só na perspectiva dos enteógenos, mas também no meio industrial, o saber tradicional de comunidades indígenas ou locais começou a adquirir destaque economicamente. Do contrário não haveria razão de tal tema ser contemplado em argumentações que tratam do comércio internacional e comportado nos artigos da OMC e no Acordo Trips.

Para se pensar na questão de foco do artigo o saber tradicional e sua apropriação - a repartição de benefícios derivados do uso sustentável de

${ }^{5}$ CATELLI, Roberto. O mundo contemporâneo: Novalgina 70 anos. São Paulo: DBA Artes Gráficas, 1993. p. 8.

6 CATELLI, Roberto. O mundo contemporâneo: Novalgina 70 anos. São Paulo: DBA Artes Gráficas, 1993. p. 9.

${ }^{7} \mathrm{O}$ termo enteógeno diz respeito às plantas usadas como inebriantes por diferentes culturas. Foram as que inicialmente chamaram atenção para os mais diversos fins.

${ }^{8}$ OTT, Jonathan. Pharmacoteon: enteogenic drugs, their plant sources and history. $2^{\circ} \mathrm{Ed}$ Kennewick: Natural products co., 1996. p.19-79. Em sua grande maioria já com princípios ativos isolados e farmacologia sugerida. Relaxantes musculares, estimulantes, anestésicos, psicóticos, psicotrópicos, neurotóxicos entre outros.

Revista Brasileira de Direito Internacional, Curitiba, v.4, n.4, jul./dez.2006 
recursos biológicos, inclusive dos genéticos, e o acesso aos mesmos - se faz importante ressaltar o papel histórico dessas comunidades indígenas ou locais. Muito do que está preservado e muito do conhecimento ou saber tradicional se deve ao modo de vida das comunidades indígenas e locais, pois estiveram em convivência estreita como o ambiente e adotaram métodos de exploração ecologicamente viáveis comparativamente à lógica ocidental.

O conhecimento, saber ou prática tradicional é assim tido por Letícia Borges da Silva:

\begin{abstract}
"Os conhecimentos tradicionais nada mais são do que criações da mente, ou melhor, do intelecto coletivo ou cultural de um povo, provenientes do estreito relacionamento que possuem com a biodiversidade. Tais saberes têm uma aplicação prática extremamente visível, como, por exemplo, na fabricação de remédios, xampus, alimentos, adubos, inseticidas dentre outros." $\mathrm{E}$ prossegue: "As práticas tradicionais são desenvolvidas ao longo do tempo e são passadas de geração para geração. Elas permitem o manejo de plantas e animais de maneira conscientemente sustentável, com um baixo impacto ambiental". 9
\end{abstract}

De suma importância a ressalva de que o saber tradicional está estritamente ligado com os modos de vida das comunidades indígenas e locais e que, além disso, os mesmos conhecimentos são tidos como apreendidos através de práticas ambientalmente sustentáveis.

Primeiro porque a somente através da existência e das práticas dessas comunidades se pôde ter o caminho mais curto às diversas substâncias potencialmente comercializáveis e aos saberes não conhecidos até então. Em segundo lugar a conservação dessas comunidades é uma saída para a prospecção de não somente novos produtos de interesse econômico, mas também de soluções, por exemplo, para a área da saúde.

A existência dessas comunidades, sua manutenção e sua proteção assim como a da sociobiodiversidade só trouxeram frutos benéficos à humanidade. Porém com relação aos benefícios oriundos da utilização, distribuição e apropriação (ou acesso) do saber ambiental, estes não podem

\footnotetext{
${ }^{9}$ SILVA, Letícia Borges da. Os conhecimentos tradicionais das comunidades indígenas e locais face aos direitos de propriedade intelectual. In: CARVALHO, Patrícia Luciane de. (Coord.) Propriedade intelectual: estudos em homenagem à professora Maristela Basso. Curitiba: Juruá, 2005. p. 375.
} 
ser restritos a quem descobre, sintetiza e/ou vende, para que o próprio saber não se extinga em meio ao discurso e as práticas ortodoxas.

\section{CONVENÇÂO SOBRE DIVERSIDADE BIOLÓGICA}

Com a criação da Organização das Nações Unidas (ONU) após a Segunda Guerra Mundial foi proclamada uma gama de novos direitos, chamados de fundamentais: direitos humanos da primeira geração, como são chamados os direitos civis e políticos; da segunda geração, que são os econômicos, sociais e culturais; e da terceira geração que são os direitos difusos. Nos anos 80 foi criado o Programa das Nações Unidas para o Meio Ambiente (Pnuma) com a missão de viabilizar uma convenção guarda-chuva para sistematizar as atividades e abarcar outros temas dessa área. Em 91 começa a negociação formal em Nairobi da convenção que é assinada por 150 países no Rio de Janeiro em 92.

O objetivo da Rio ou Eco-92, uma das mais significativas conferências internacionais já realizadas pelas Nações Unidas, focava-se na mudança do paradigma até então predominante: desenvolvimento fomentado exclusivamente pelo crescimento econômico. Tal conferência suscitou a necessidade intermitente de atenção entre a máxima deste desenvolvimento e o ambiente. A alavanca da conferência foi o efeito estufa, que já trazia elementos científicos significativos relativos ao aumento da temperatura do globo devido à emissão de gases poluentes. Dentre esses gases o mais preocupante atualmente é o $\mathrm{CO} 2$.

Mas não exclusivamente à questão do clima se deve a relevância da CDB (Convenção de Diversidade Biológica).

\footnotetext{
"O grande avanço está em transcender temas como a conservação e o uso dos recursos biológicos e comportar outros como o acesso aos recursos genéticos e a repartição do uso desses recursos, biossegurança e biotecnologia, acesso e transferência de tecnologia." ${ }^{10}$
}

10 BENSUSAN, Nurit. Convenção sobre Diversidade Biológica. In: CAMARGO, Aspásia; CAPOBIANCO, José Paulo Ribeiro; OLIVEIRA, José Antonio Puppim de. (Orgs.) Meio ambiente Brasil: avanços e obstáculos pós Rio-92. 1a ed. São Paulo: Estação Liberdade, 2002. p.69

Revista Brasileira de Direito Internacional, Curitiba, v.4, n.4, jul./dez.2006 
Sob a égide da soberania nacional a CDB baseia-se em três pilares: a conservação da biodiversidade, o uso sustentável desses componentes da biodiversidade e a repartição dos benefícios oriundos do uso sustentável de componentes da biodiversidade. Nesse artigo procurar-se-á salientar esse ultimo pilar que trata da repartição dos benefícios.

A CDB é o principal instrumento internacional de proteção da diversidade biológica, tanto tangível quanto intangível, e consequentemente, e preconiza a respeito do conhecimento tradicional e das populações indígenas ou locais, como dispõe o artigo 8 intitulado Conservación In-situ em seu inciso(j):

\footnotetext{
“ j) Con arreglo a su legislación nacional, respetará, preservará y mantendrá los conocimientos, las innovaciones y las prácticas de las comunidades indígenas y locales que entrañen estilos tradicionales de vida pertinentes para la conservación y la utilización sostenible de la diversidad biológica y promoverá su aplicación más amplia, con la aprobación y la participación de quienes posean esos conocimientos, innovaciones y prácticas, y fomentará que los beneficios derivados de la utilización de esos conocimientos, innovaciones y prácticas se compartan equitativamente;," 11
}

O principal objetivo da CDB é a formalização da discussão em países desenvolvidos de um lado, e de outro os em desenvolvimento. Resumindo, o grande abismo norte-sul. Enquanto os desenvolvidos são detentores do desenvolvimento tecnológico e de notável poderio econômico, o resto do mundo, que por sinal comporta a maior parte da pobreza, detém a biodiversidade.

Sob essa ótica, a CDB se propõe como um instrumento de "cooperação entre os países para a conservação e utilização sustentável dos recursos biológicos existentes no Planeta" ${ }^{12}$. Em outras palavras: a não conciliação de interesses entre países do norte e do sul, vêm a prejudicar não

\footnotetext{
11 Convention on Biological Diversity. Artículo 8. Acessado no endereço http://www.biodiv.org/convention/articles.shtml?lg=0\&a=cbd-08 em 11/11/2006. Há inclusive um working group trabalhando para a viabilização instrumental do artigo 8.

${ }^{12}$ SILVA, Letícia Borges da. Os conhecimentos tradicionais das comunidades indígenas e locais face aos direitos de propriedade intelectual. In: CARVALHO, Patrícia Luciane de. (Coord.) Propriedade intelectual: estudos em homenagem à professora Maristela Basso. Curitiba: Juruá, 2005. p. 379.
} 
só ao ambiente, mas como um integrante deste mesmo: o homem. Se os países do norte são mais desenvolvidos, os do sul ainda possuem a abundância em recursos naturais; então que acordem e troquem tecnologia por matéria prima. E seguindo o foco da análise, que a troquem por acesso ao conhecimento tradicional, como propõe a cooperação preconizada na CDB.

Mesmo com toda coerência do discurso os países desenvolvidos parecem não abrir mão nem da transferência de tecnologia, nem da repartição de benefícios, e menos ainda de custos para acessar a biodiversidade. No artigo 15 da CDB tem-se a indicação sobre o acesso aos recursos genéticos, no art.16 o acesso e a transferência de tecnologia, no art.19 o manejo da biotecnologia e a distribuição de seus benefícios, seguidos pelos incentivos financeiros nos arts. 20 e 21.

Pode-se facilmente observar que a CDB se apresenta como um mecanismo de proteção socioambiental para países mais pobres em relação aos mais ricos, ainda que se exijam notáveis esforços nacionais. Assim coloca o fim artigo 15 intitulado de Acesso à Recursos Genéticos:

\footnotetext{
"4. Cuando se conceda acceso, éste será en condiciones mutuamente convenidas y estará sometido a lo dispuesto en el presente artículo. 5. El acceso a los recursos genéticos estará sometido al consentimiento fundamentado previo de la Parte Contratante que proporciona los recursos, a menos que esa Parte decida outra cosa.

6. Cada Parte Contratante procurará promover y realizar investigaciones científicas basadas en los recursos genéticos proporcionados por otras Partes Contratantes con la plena participación de esas Partes Contratantes, $y$ de ser posible em ellas.

7. Cada Parte Contratante tomará medidas legislativas, administrativas o de política, según proceda, de conformidad con los artículos 16 y 19 y, cuando sea necesario, por conducto del mecanismo financiero previsto en los artículos 20 y 21, para compartir en forma justa y equitativa los resultados de las actividades de investigación y desarrollo y los beneficios derivados de la utilización comercial y de otra índole de los recursos genéticos con la Parte Contratante que aporta esos recursos. Esa participación se llevará a cabo en condiciones mutuamente acordadas." 13
}

Segundo Nurit Besusan há uma estrutura internacional criada pela CDB para assistir à sua implementação. A secretaria que está localizada em Montreal, a Conferência das Partes (COP) cuja ultima reunião se deu em Convention on Biological Diversity. Artículo $15 . \quad$ Disponível no endereço
http://www.biodiv.org/convention/articles.shtml?lg=0\&a=cbd-15 em 22/08/2006.

Revista Brasileira de Direito Internacional, Curitiba, v.4, n.4, jul./dez.2006 
Curitiba em 2006, o corpo Subsidiário de Assistência Científica, Técnica e Tecnológica (SBSTTA), o mecanismo de troca de informações e cooperação (CHM - Clearing-House Mechanism), o Fundo Global para o Meio Ambiente (GEF) entre outros corpos subsidiários. A administração da Convenção é sustentada pelo fundo da CDB que funciona desde 1995 e cresce em arrecadação ano a ano ${ }^{14}$.

Apesar de 183 paises já terem assinado a CDB e destes 168 ratificaram, as implicações econômicas para os países desenvolvidos se apresentam como principal barreira para o aumento da cooperação proposta pela Convenção. Esse conflito se evidencia claramente com a ausência dos Estados Unidos como membro, ao passo que a implementação da CDB caminha muito lentamente. Foram feitas tentativas pelo secretariado executivo no intuito de promover uma discussão para elaborar um plano de ação.

Se a divisão Norte-Sul com os grandes lobbies, salta aos olhos em questões de biossegurança, como nos debates em torno do Protocolo de Cartagena e da patenteabilidade da biodiversidade; tal divisão ou hiato se explicita mais ainda no tangente ao acesso e apropriação de recursos genéticos, conhecimentos e práticas tradicionais e à repartição de benefícios.

\section{ORGANIZAÇÃO MUNDIAL DO COMÉRCIO}

Se por um lado a CDB propugna essa visão "sulista" de cooperação e de repartição de benefícios, por outro, na esfera do comércio internacional onde operam as forças das grandes empresas, surgidas nos países desenvolvidos, quem rege as normas é a OMC. E é nesse campo que os países em desenvolvimento têm as maiores dificuldades de atingir objetivos de função socioambiental.

O atual sistema de propriedade intelectual está fundado numa complexa relação de normas acordadas e costumes internacionais. Não é em

\footnotetext{
${ }^{14}$ Em 1999 foi de US\$8.303.000; em 2000 de US\$8.998.600; em 2001 de US\$8.594.000; em 2002 de US\$10.049.900. BENSUSAN, Nurit. Convenção sobre Diversidade Biológica. In: CAMARGO, Aspásia; CAPOBIANCO, José P. Ribeiro; OLIVEIRA, José A. Puppim de. (Org.) Meio ambiente Brasil: avanços e obstáculos pós Rio-92. 1르 ed. São Paulo: Estação Liberdade, 2002. p. 73.
}

Revista Brasileira de Direito Internacional, Curitiba, v.4, n.4, jul./dez.2006 
vão que as Convenções de Berna e Paris sejam marcos na história do direito internacional. Ao contrário dos tratados e convenções celebrados até então, estes tinham além da costumeira pretensão de contribuir para a formação da comunidade internacional, fins jurídicos em si e nos indivíduos ${ }^{15}$. Vale-se então para essa investigação um breve retrospecto.

Até a revolução Francesa em 1789 não havia meios jurídicos que protegessem ou autores de obras literárias, nem artísticas e muito menos práticas tradicionais. A maior pena seria o constrangimento. No século XIX são criados os direitos da personalidade e os da propriedade intelectual na qual esta última categoria regulava as relações imateriais entre as pessoas ${ }^{16}$. Assim deu-se a proteção dos direitos do autor e conexos, e os direitos da propriedade industrial. Em outro âmbito fazia-se necessário proteger os interesses da sociedade estabelecendo-se assim a União de Paris e a União de Berna que funcionavam no mesmo Bureaux e propunham preceitos demonstrando razoabilidade incluindo limitações e exceções, como no caso da licença compulsória.

Após a Segunda Guerra Mundial as Uniões não acompanharam o pósguerra, surgiu o Gatt que tratava sutilmente do objeto em 1947 e a ONU em 1945 que criou agências especializadas para promover conferências. Os Bureaux foram transformados na Organização Mundial para a Propriedade Intelectual (Ompi) em 1967 e o General Agreement on Tariffs and Trades (Gatt) ampliou-se com as negociações da rodada do Uruguai (1986-1993), depois com os Acordos de Marraqueche (1994) e em 1995 foi criada a OMC.

A OMC e a Ompi tem relações complementares e foram objeto de Acordo firmado em Genebra em 1995 chamado de Trade-Related Aspects of

\footnotetext{
${ }^{15}$ Comentário de Hans Kelsen apud Maristela Basso no intuito de salientar a capacidade dos tratados internacionais em criar direitos para os indivíduos. Tal pretensão é tida como marco histórico na ordem jurídica internacional. Com relação ao histórico da evolução jurídica até a Segunda Guerra Mundial nesse assunto vide: BASSO, Maristela. O Direito Internacional da Propriedade Intelectual. Porto Alegre: Livraria do Advogado, 2000. p. 64-125. Também se pode encontrar esse histórico que remonta à Roma antiga em: NETTO, José Cretella.Taking Trips Throught Human History: dos Direitos Absolutos sobre a propriedade aos Direitos Fundamentais. In: MENEZES, Wagner (Organizador). O Direito Internacional e o Direito Brasileiro: homenagem a José Francisco Rezek. ljuí: Editora Unijuí,2004. p. 568-592.

${ }^{16}$ NETTO, José Cretella.Taking Trips Throught Human History: dos Direitos Absolutos sobre a propriedade aos Direitos Fundamentais. In: MENEZES, Wagner (Org.) O Direito Internacional e o Direito Brasileiro: homenagem a José Francisco Rezek. ljuí: Editora Unijuí, 2004. p. 572.
}

Revista Brasileira de Direito Internacional, Curitiba, v.4, n.4, jul./dez.2006 
Intelectual Property Rights (Trips). Este Acordo estabelece: direitos de autor e direitos conexos, marcas de produtos e de serviços, indicações geográficas, desenhos industriais, patentes e layouts de circuitos integrados.

Ainda que, se tente argumentar através do artigo $8^{\circ}$ do Acordo, ou seja, que o Trips engloba princípios do Gatt como o da primazia da proteção à saúde pública, ou mesmo da promoção do interesse público e assim por diante; não se pode esperar por boa-fé quando principalmente os interesses em proteger os direitos do intelecto, só acabam por beneficiar autores, marcas e detentores de patentes, que em grande maioria estão localizados na parte norte do globo. A título de exemplo, com relação à pirataria, principalmente de softwares e de produtos audiovisuais, há grande esforço em fazerem-se cumprir os dispositivos legais como se pode acompanhar cotidianamente pelos meios de comunicação no Brasil.

Contudo, é interessante perceber: uma invenção, marca ou patente assim que registrado em nome de pessoa ou empresa possui reconhecimento por todos signatários do Trips que correspondem à todos participantes da $\mathrm{OMC}^{17}$. No caso do patenteamento às formas de vida é vetado, com exceção dos microorganismos, e processos essencialmente biológicos para a produção de plantas e animais assim como outros processos não-biológicos e microbiológicos. Dessa maneira colocado no art.27.3b do Trips. É nesse furo, na exclusão de certas categorias de vida, que entram as sementes GURTs mais conhecidas como Terminator $^{18}$, produzidas e patenteadas pela maior empresa do ramo da biotecnologia ${ }^{19}$ e outras como a BASF, Syngenta e Dupont.

Fica clara a dificuldade de trazer à tona nas rodadas da OMC um debate enfático no sentido de proteção dos direitos de comunidades locais ou indígenas, mesmo com a inclusão de temas como a biopirataria. Se um país em desenvolvimento não possui pesquisa suficiente para produzir nem mesmo

\footnotetext{
17 SILVA, Letícia Borges da. Os conhecimentos tradicionais das comunidades indígenas e locais face aos direitos de propriedade intelectual. In: CARVALHO, Patrícia Luciane de. (Coord.) Propriedade intelectual: estudos em homenagem à professora Maristela Basso. Curitiba: Juruá, 2005. p.381.

${ }^{18}$ Tais sementes produzem plantas que, por sua vez, produzem sementes estéreis.

${ }^{19}$ A Monsanto é a maior empresa do ramo da biotecnologia no mundo.
}

Revista Brasileira de Direito Internacional, Curitiba, v.4, n.4, jul./dez.2006 
os remédios que se enquadram na argumentação da licença compulsória, quem dirá orçamento suficiente para proteger internamente seus recursos naturais através de políticas de monitoramento e controle de estrangeiros no país. Nem as empresas sediadas em países desenvolvidos e nem as pessoas vítimas de doenças endêmicas esperam que as pesquisas e o desenvolvimento de novas drogas acabem ou mesmo diminuam de ritmo.

Na rodada de Doha em 2001 optou-se por uma postura de pressão por parte dos países em desenvolvimento, encabeçados pela Índia e pelo Brasil, e na rodada adotou-se uma declaração razoável com relação aos fármacos. 0 primeiro aspecto prescreve que o acordo Trips não deve impedir os membros de adotarem medidas para proteger a saúde pública. Em segundo lugar os membros devem atentar-se à possibilidade de utilização das flexibilidades (licença compulsória e importação paralela) contidas no Trips. Os dois primeiros pontos configuram a "usual retórica diplomática vazia e pouco eficaz" $^{20}$ mas no que concerne ao prolongamento do prazo para quebra de patentes pelos países em desenvolvimento até 2016, terceiro ponto, evidenciase o quanto a sutileza do discurso norte ainda pode se manter sutil.

Se bem que em 2003 a importação paralela fora autorizada a qualquer membro da OMC, mesmo quando 23 países desenvolvidos comprometeram-se a não realizar tal tipo de exportação e outros 12 afirmaram fazê-lo somente em caso de emergência. Apesar da licença compulsória e da importação paralela estar permitidas no acordo desde que em consonância aos critérios necessários, é relevante salientar, no caso da importação especificamente que para a tramitação na OMC exige-se: a quantidade de medicamentos a serem importados, o balanço das operações de comércio internacional destes para a comprovação da boa fé de ambas as partes e a explicitação dos motivos de tal importação.

Vale lembrar que a conquista diplomática na rodada de Doha é inédita, todavia a Declaração a respeito dos fármacos não sai do papel principalmente

\footnotetext{
${ }^{20}$ São estas posturas que acabam por prolongar alguma discussão ou atrasar alguma decisão. NETTO, José Cretella.Taking Trips Throught Human History: dos Direitos Absolutos sobre a propriedade aos Direitos Fundamentais. In: MENEZES, Wagner. (Org.). O Direito Internacional e o Direito Brasileiro: homenagem a José Francisco Rezek. ljuí: Editora Unijuí, 2004. p. 585.
}

Revista Brasileira de Direito Internacional, Curitiba, v.4, n.4, jul./dez.2006 
pela questão da importação paralela. Como bem colocado: "A controvérsia central diz respeito ao parágrafo 6 da Declaração de Doha, que permite a terceiros produzir, vender e exportar medicamentos patenteados e demais tecnologias de saúde para atender as necessidades de saúde pública" ${ }^{21}$.

Voltando ao assunto foco deste artigo. Para usar a terminologia mais adequada seria: o conhecimento tradicional associado ao patrimônio genético. Como não se vê no horizonte um acordo que vá contemplar uma nova forma de patenteabilidade fora dos padrões ocidentais, busca-se a inclusão do tema do acesso aos recursos biológicos e genéticos, para assim serem abarcados no Trips.

A última tentativa foi grupal: Brasil, China, Colômbia, Cuba, Índia, Paquistão, Peru, Tailândia e Tanzânia no documento ${ }^{22}$ de 05 de Julho de 2006 tratando da relação entre o Trips e a CBD. No parágrafo segundo fizeram a proposta de revisão do artigo 29 colocam:

\begin{abstract}
"Quando a matéria de interesse estiver sujeita à aplicação de patente, sendo esta derivada ou desenvolvida com recursos biológicos e/ou conhecimento tradicional associado, os membros devem exigir ao requerente divulgar o país que fornece os recursos e/ou o conhecimento tradicional associado, de quem foi obtido no país fornecedor, e, reconhecido após o inquérito razoável, o país de origem. Os membros também devem exigir que os requerentes forneçam informação, incluindo evidência da conformidade com as exigências legais aplicáveis no país fornecedor, de consentimento previamente informado, para o acesso e a justa repartição de benefícios emanarem da utilização seja comercial ou outra, destes recursos e/ou conhecimento tradicional associado.."23
\end{abstract}

\footnotetext{
${ }^{21}$ FRIEDRICH, Tatyana Scheila; RAMINA, Larissa. Direito Internacional e Direito Interno nas relações de propriedade intelectual. $O$ acordo Trips e a lei brasileira de patentes. In: MENEZES, Wagner. (Org.) O Direito Internacional e o Direito Brasileiro: homenagem a José Francisco Rezek. ljuí: Editora Unijuí,2004. p.608

${ }^{22}$ Trata sobre o artigo 27.3b.

23 Tradução livre do autor: "Where the subject matter of a patent application concerns, is derived from or developed with biological resources and/or associated traditional knowledge, Members shall require applicants to disclose the country providing the resources and/or associated traditional knowledge, from whom in the providing country they were obtained, and, as known after reasonable inquiry, the country of origin. Members shall also require that applicants provide information including evidence of compliance with the applicable legal requirements in the providing country for prior informed consent for access and fair and equitable benefit-sharing arising from the commercial or other utilization of such resources and/or associated traditional knowledge". World Trade Organization. IP/C/W/474. Disponível no sítio http://docsonline.wto.org/DDFDocuments/t/IP/C/W474.doc em 23/08/2006.
} 
No ano de 2006, mês da realização da COP8-MOP3, até Julho circularam seis documentos relacionados à questão da CDB com o Acordo da OMC-Trips, incluindo o assunto do saber tradicional ou local. No ano de 2005 foram oito relativos ao tema. A maioria dos documentos trata dessa polêmica relativa à revisão do art.29 intitulado Condition on Patent Applicants (Condições para os Requerentes de Patentes) que trata da proteção do saber tradicional e da revisão do artigo 27.3b (o furo das GURTs). Duas opções são as possíveis metas a atingir, no sentido do discurso.

Por um lado, que é improvável, preconizar a idéia da proibição patenteabilidade de todas as formas de vida incluindo microorganismos e processos que produzem plantas, animais e outros organismos vivos até porque isso já acontece. Uma segunda probabilidade escassa seria proibir o patenteamento de substâncias derivadas do saber tradicional. É entre essas duas opções que supostamente a relação da CDB com a OMC-Trips tende a se harmonizar ${ }^{24}$, lógico que, o prazo depende do andamento das negociações com a introjeção de temas da CDB na discussão comercial. É o mais palatável a todos apesar da resistência explicita de uma minoria em que aparecem os EUA e a Suíça.

\section{CONSIDERAÇÕES FINAIS}

Com um breve sobreolhar já é possível notar ao menos que há uma divisão mais do que clara no mundo. Que seja chamada de divisão Norte-Sul, hiato entre países desenvolvidos e em desenvolvimento, pobres e ricos dentre outros. É o que se pode notar em uma avaliação dos dois pontos de vista, sobre o mesmo assunto que é o enfoque deste comentário: o saber tradicional. Ao iniciar esta exposição havia sido colocada uma questão paradoxal que segue da seguinte forma.

\footnotetext{
${ }^{24}$ A própria OMC produz no Conselho para o Trips resumos dos assuntos e posições tomadas pelos países, em grupo ou não. Sobre a questão da relação específica entre a regulamentação CDB e a OMC concernente ao saber tradicional e o folclore há um documento importante antecedente a COP8MOP3. O IP/C/W/386/Rev1 de 8 de Fevereiro que versa sobre a interrelação do tema em ambos os foros.
}

Revista Brasileira de Direito Internacional, Curitiba, v.4, n.4, jul./dez.2006 
A propriedade industrial inicialmente e a propriedade intelectual num segundo momento, com máximas que residem na OMC-Trips, vem historicamente de forma a regulamentar a propriedade de um particular em detrimento ao geral ou ao público. Já a CDB mais incipiente e com menos know-how, fundada nas novas gerações dos direitos, vêm no intuito de regulamentar o público em favor ao particular.

Então se percebe que na CDB os países não desenvolvidos anseiam pela exploração dos recursos naturais e acesso aos mercados internacionais; a contrapartida é a luta pela proteção da natureza e os subsídios a uma agricultura altamente avançada e mecanizada. $\mathrm{Na}$ OMC os países desenvolvidos querem acesso à biodiversidade e proteção dos direitos de objeto imaterial, na outra ponta a transferência de tecnologia e a repartição de benefícios. É obvio que internamente nos Estados as opiniões não são unânimes e a comparação é didática ao recorte do argumento. Paradoxal parecer que cada extremo está direcionando o discurso em sentidos opostos.

Quatro pontos de tensão ${ }^{25}$ podem ser evidenciados entre a CDB e o Acordo OMC-Trips. O primeiro é a divergência entre a questão da biopirataria. A CDB deixa a cargo dos Estados a observância do preceito do consentimento prévio das comunidades indígenas ou locais, o Acordo Trips não suscita nenhuma questão sobre o consentimento prévio para que possam ser os conhecimentos posteriormente protegidos.

$\mathrm{Na}$ que tange a quem pertencem os recursos biológicos o Trips apresenta os direitos de propriedade intelectual para tutelar os recursos e a limitação das licenças compulsórias no caso do interesse nacional. A CDB coloca que os Estados são soberanos sobre seus recursos biológicos.

Terceiro ponto é a que utilização dos recursos biológicos e também dos conhecimentos tradicionais deve ser fundado na divisão eqüitativa dos

\footnotetext{
${ }^{H}$ POZ, Maria Ester Dal; SILVEIRA, José Maria D.F.; FONSECA, Maria da Graça. Direitos da Propriedade Intelectual: um processo em construção. In: SILVEIRA, José Maria F.Jda; POZ, Maria Ester dal; ASSAD, Ana Lucia D. (Orgs.) Biotecnologia e recursos genéticos: desafios e oportunidades para o Brasil. Campinas: Instituto de Economia/FINEP, 2004. p.358. Estes quatro pontos comparativos aparecem na forma de um quadro explicativo na bibliografia indicada. Há também uma relevante discussão no viés econômico, de saúde, empresarial, do agronegócio, político entre outras áreas sobre a questão específica da biotecnologia e recursos genéticos.
}

Revista Brasileira de Direito Internacional, Curitiba, v.4, n.4, jul./dez.2006 
benefícios advindos desse uso. No caso do Trips o uso e exploração dos recursos estão sujeitos às regras do direito da propriedade intelectual e não há nenhuma previsão para assuntos à repartição de benefícios.

Os Estados particulares têm por obrigação zelar pelo ambiente e usá-lo sustentavelmente, pois esta é uma preocupação de toda humanidade. Segundo o Acordo Trips a saúde pública e também a segurança alimentar estão à mercê dos direitos de propriedade intelectual e aos interesses privados. Nesse caso o conflito se sucede através das barreiras não-tarifárias no comércio internacional.

A questão dos fármacos pode ser tida como uma ponta do iceberg que ainda está por vir. Nem tudo é pessimismo. São inegáveis os avanços relacionados aos foros internacionais que regulamentam as relações entre os Estados. Através deles que se podem travar as lutas acerca dos diferentes interesses componentes de outra diversidade: a dos seres humanos.

Pragmaticamente o mais pungente para o tema no Brasil são os investimentos e esforços na área de pesquisa, legislação e fiscalização evitando e a biopirataria ou apropriação indevida e controlando o acesso aos recursos genéticos. Busca-se assim a mesma proteção de direitos que se presta à softwares, produtos audiovisuais e cultivares, por exemplo, ante à pirataria dos recursos genéticos associado ao saberes ambientais.

Como explicita Astrid Heringer:

"O Brasil, além de outros países latino-americanos, possui uma imensa reserva de biodiversidade que está sendo explorada e contrabandeada aos maiores centros de pesquisa do mundo. (...)30\% dos medicamentos existentes hoje são resultantes da biotecnologia.

O Brasil é ineficiente em tecnologia e as reservas de biodiversidades existentes no território nacional poderiam servir como meio de barganha para efetuar transferências de tecnologia". ${ }^{26}$

\section{REFERÊNCIAS}

ASTRID, Heringer. Patentes farmacêuticas \& Propriedade Intelectual no contexto internacional. $1^{\text {a }}$ ed. Curitiba: Juruá, 2005. ${ }^{26}$ ASTRID, Heringer. Patentes farmacêuticas \&Propriedade Intelectual no contexto
internacional. $1^{\underline{a}}$ ed. Curitiba: Juruá, 2005. p.111.

Revista Brasileira de Direito Internacional, Curitiba, v.4, n.4, jul./dez.2006 
BASSO, M. O Direito Internacional da propriedade intelectual. Porto Alegre: Livraria do Advogado, 2000.

CAMARGO, Aspásia; CAPOBIANCO, João Paulo Ribeiro; OLIVEIRA, José Antonio Puppim de. (Org.) Meio ambiente Brasil: avanços e obstáculos pós Rio92. $1^{\text {a }}$ ed. São Paulo: Estação Liberdade, 2002.

CATELLI, R. O mundo contemporâneo: Novalgina 70 anos. São Paulo: DBA Artes Gráficas, 1993.

Convention on Biological Diversity. Artículo 15. Disponível no endereço http://www.biodiv.org/convention/articles.shtml?lg=0\&a=cbd-15 em 22/08/2006.

Artículo 8. Acessado no endereço http://www.biodiv.org/convention/articles.shtml?lg=0\&a=cbd-08 em 11/11/2006.

FRIEDRICH, Tatyana Scheila; RAMINA, Larissa. Direito Internacional e Direito Interno nas relações de propriedade intelectual. $O$ acordo Trips e a lei brasileira de patentes. In: MENEZES, Wagner. (Org.) O Direito Internacional e o Direito Brasileiro: homenagem a José Francisco Rezek. ljuí: Editora Unijuí,2004.

LEFF, Enrique. Epistemologia ambiental. São Paulo: Editora Cortês,2001.

NERO, Patrícia Aurélia Del. A Propriedade Intelectual da Biotecnologia In: CARVALHO, Patrícia Luciane de. (Coord.) Propriedade intelectual: estudos em homenagem à professora Maristela Basso. Curitiba: Juruá, 2005

NETTO, José Cretella. Taking trips throught human history: dos Direitos Absolutos sobre a propriedade aos Direitos Fundamentais. In: MENEZES, W. (Org.) O Direito Internacional e o Direito Brasileiro: homenagem a José Francisco Rezek. ljuí: Editora Unijuí,2004.

OTT, Jonathan. Pharmacoteon: enteogenic drugs, their plant sources and history. $2^{\circ}$ Ed Kennewick: Natural products co., 1996. 
POZ, Maria Ester Dal; SILVEIRA, José Maria D.F.; FONSECA, Maria da Graça. Direitos da Propriedade Intelectual: um processo em construção. In: SILVEIRA, José Maria F.Jda; POZ, Maria Ester dal; ASSAD, Ana Lucia D. (Orgs.) Biotecnologia e recursos genéticos: desafios e oportunidades para o Brasil. Campinas: Instituto de Economia/FINEP, 2004.

SILVA, Letícia Borges da. Os conhecimentos tradicionais das comunidades indígenas e locais face aos direitos de propriedade intelectual. In: CARVALHO, P.L. de. Org. Propriedade intelectual: estudos em homenagem à professora Maristela Basso. Curitiba: Juruá, 2005.

World Trade Organization. IP/C/W/368Rev.1. Acesso ao http://docsonline.wto.org/DDFDocuments/t/IP/C/W368R1.doc em 10/10 /2006.

IP/C/W/474. Disponível no sítio http://docsonline.wto.org/DDFDocuments/t/IP/C/W474.doc em 23/08/2006. 